\title{
A Educação do Campo na pesquisa educacional brasileira
}

\author{
Gustavo Cunha de Araújo ${ }^{1}$, Cícero da Silva ${ }^{2}$ \\ ${ }^{1}$ Universidade Federal do Tocantins - UFT, Departamento de Educação do Campo. Avenida Nossa Senhora de \\ Fátima, 1588, Centro. Tocantinópolis, Brasil. rbec@uft.edu.br. ${ }^{2}$ Universidade Federal do Tocantins - UFT.
}

A Revista Brasileira de Educação do Campo - RBEC, ISSN 2525-4863, periódico do Departamento de Educação do Campo, da Universidade Federal do Tocantins, campus de Tocantinópolis, lança o seu segundo número do volume 2, referente ao segundo semestre de 2017. Este número traz 15 artigos, 2 ensaios, além de uma resenha, aprovados dentre os manuscritos recebidos ao longo do ano de 2017. Novamente, a revista conta com artigos internacionais de diferentes instituições de ensino superior, sendo 2 de Cuba, e 1 da Bolívia, que abordam diferentes temáticas em diálogo com a Educação do Campo.

O conjunto de trabalhos que integra esse número corrobora a importância da RBEC para a pesquisa em Educação do Campo, assim como para a produção científica em educação no Brasil. Hoje, esse periódico possibilita agrupar, em um mesmo espaço, pesquisas de diferentes abordagens teórico-metodológicas desenvolvidas no âmbito do contexto educacional do campo. Portanto, essa especificidade da revista ajuda tanto os pesquisadores na divulgação dos resultados de suas investigações quanto os leitores interessados nessa temática.

Iniciamos a apresentação dos artigos deste número com o trabalho "Interculturalidade na formação de professores do campo: análise de uma experiência" - de autoria de Marques, da Universidade Federal dos Vales do Jequitinhonha e Mucuri UFVJM, que faz uma reflexão teórica acerca de um curso de licenciatura em Educação do Campo de uma universidade federal brasileira sob a perspectiva teórica da interculturalidade. $\mathrm{O}$ autor pretende neste artigo promover propostas e debates a respeito da interculturalidade $\mathrm{e}$ formação de professores na Educação do Campo.

$\mathrm{Na}$ pesquisa seguinte, de autoria de Albuquerque, Pássaro e Figueirêdo, da Universidade Regional do Cariri - URCA, intitulada "Educação do Campo: percalços na construção do curso de licenciatura em Educação do Campo na Universidade Regional do Cariri", os pesquisadores problematizam dificuldades e desafios a respeito do desenvolvimento do curso de Licenciatura em Educação do Campo da URCA, principalmente no que se refere à formação de professores para a Educação do Campo.

No artigo "Educação do Campo e o programa Projovem Campo em Planaltina/DF", de Figueiredo e Freitas, da Universidade de Brasília - UnB, as autoras analisam a importância da Política Nacional de Juventude, principalmente relacionada ao Programa Projovem Campo, que, segundo as pesquisadoras, tem como objetivo possibilitar aos jovens de 18 a 29 anos a concluírem seus estudos. As autoras concluem que os principais obstáculos encontrados pelos jovens se referem ao não cumprimento de ações estabelecidas nessa política, como, por exemplo, refeições inadequadas aos estudantes, falta de espaço 
físico e de materiais para a sala de acolhimento, além do não pagamento de bolsa auxílio aos estudantes.

O tema formação de professores para o campo pode ser encontrado na pesquisa de Azinari e Peripolli, da Universidade do Estado de Mato Grosso - UNEMAT, no artigo intitulado "Uni-versidade multi-versa? Reflexões sobre a formação de professores do curso de Licenciatura em Pedagogia do Campo no distrito de Caramujo, Cáceres/MT". Os autores analisam uma experiência desenvolvida no curso de Licenciatura em Pedagogia do Campo, em Mato Grosso. Com base nos resultados, eles afirmam nesse estudo que foi possível entender e pensar alguns conceitos relacionados à formação de professores para a Educação do Campo, bem como questões relacionadas às escolas existentes no meio rural.

Temas relacionados à saúde também são objetos de estudo para a Educação do Campo, como a pesquisa "Contribuições da Terapia Ocupacional Social nas escolas do campo" de autoria de Farias e Faleiro, da Universidade Federal de Goiás - UFG. Nesse trabalho, os pesquisadores defendem que a Terapia Ocupacional Social (TOS) pode possibilitar desconstruir as contradições dos sistemas de ensino, por meio de atividades que envolvem dinâmicas coletivas, desenvolvimento de projetos, entre outros. Assim, os autores concluem que o uso da TOS nas escolas do campo pode assegurar o acesso da população camponesa aos seus direitos sociais.

O artigo internacional "El Padre Carlos Felipe Beltrán: planteamientos de una educación indígena y bilingüe en Bolivia (1862-1892)", de Daza, do Instituto de Estudios Bolivianos - UMSA, Bolívia, busca descrever e analisar como se deu a educação indígena na Bolívia, a partir da experiência e contribuição do Padre Carlos Felipe Beltran. A pesquisa constatou que Beltran teve papel fundamental para o desenvolvimento da alfabetização nas línguas Aymara e Quechua para a população indígena boliviana da época (1862-1892).

"Movimento dos Trabalhadores Rurais Sem Terra e a formação para a igualdade de gênero", de autoria de Pessôa e Dal Ri, da Universidade Estadual Paulista Julio de Mesquita Filho - UNESP, campus de Marília, analisa a igualdade de gênero presente no Movimento dos Trabalhadores Rurais Sem Terra (MST). Por meio de uma pesquisa documental e bibliográfica, as autoras identificaram que, desde a criação do MST, é possível encontrar textos teóricos a respeito da participação das mulheres na produção, nas coordenações e ações políticas do movimento. Nesse sentido, concluem que o MST criou um Setor de Gênero voltado à promoção da igualdade de gênero e à participação igualitária.

O Projeto Político Pedagógico (PPP) na Educação do Campo é o tema da pesquisa intitulada "O significado do Projeto Político Pedagógico na construção de ações e relações participativas na educação do campo" desenvolvida por Caetano e Silva, da Universidade Federal de Mato Grosso - UFMT. Os autores analisam qual é a compreensão de professores que atuam numa escola do campo a respeito do Projeto Político Pedagógico, entendido numa perspectiva participativa e democrática. Os pesquisadores destacam ainda nessa pesquisa que, além de ser um documento necessário e importante na organização e tomadas de decisões na escola, é necessário que a comunidade escolar tenha participação efetiva na elaboração desse projeto e na validação das decisões tomadas pela gestão escolar.

"A contribuição da História das Ciências para formação de educadores do campo", de Mendes e Grilo, da Universidade Federal do Recôncavo da Bahia - UFRB, apresenta um estudo dialético a respeito da importância da abordagem externalista na formação de professores do campo. A pesquisa concluiu que as atividades desenvolvidas a partir dessa abordagem possibilitaram novas formas de se compreender a evolução dos conceitos de Ciência, em consonância com a Educação do Campo.

Já o artigo intitulado "Políticas públicas de gestão da Educação do Campo no contexto de reestruturação organizacional do Pronera", das autoras Lélis, Silva e Amaral, vinculadas à Universidade Estadual de Montes Claros - Unimontes e à Universidade Federal 
de Uberlândia - UFU, tem por objetivo problematizar a centralidade assumida pelo Instituto Nacional de Colonização e Reforma Agrária (Incra)/Programa Nacional de Educação na Reforma Agrária (Pronera) na gestão da Educação do Campo, secundarizando o papel do Ministério da Educação (MEC). Trata-se de uma pesquisa documental, cujas análises focalizam indícios dessa ação a partir do Decreto n. 7.352/2010 e dos Manuais de Operações do Programa. Os resultados do estudo mostram que, desde a criação do Pronera, em 1998, há indícios de afastamento da gestão da Educação do Campo do MEC, sendo que tal processo ganhou força em 2001, quando o Incra assumiu a gestão do Pronera. As pesquisadoras ressaltam ainda que a transferência da responsabilidade pela gestão da Educação do Campo do MEC para o MDA/Incra, por meio do Pronera, pode trazer implicações de natureza político, social, educacional e econômico, apontando para um esvaziamento da missão do MEC, em relação à educação pública.

Em "Panorama bibliométrico das teses e dissertações sobre educação indígena", de Maroldi, Lima, Hayashi e Hayashi, da Universidade Federal de Rondônia - UNIR e Universidade Federal de São Carlos - UFSCAR, os autores apresentam um panorama bibliométrico da produção científica sobre a educação indígena presente nas teses e dissertações da Biblioteca Digital Brasileira de Teses e Dissertações (BDTD/IBICT). O estudo foi desenvolvido por meio da metodologia bibliométrica e o corpus traz 173 trabalhos de pós-graduação defendidos no país entre os anos de 1996 a 2016. Os resultados mostram que as regiões Sudeste e Sul, respectivamente, concentram o maior número de trabalhos e que a área da Educação é majoritária na produção científica das teses e dissertações recuperadas.

No artigo "O trabalho como princípio educativo no MST: um estudo de caso do Assentamento Padre Réus", de autoria de Lopes e Moretti, da Universidade de Santa Cruz do Sul - UNISC, o objetivo da investigação é apreender quais são as novas práticas sociais, alicerçadas em um processo de educação que se desenvolve no movimento e que possibilitam pensar uma pedagogia da luta do movimento social. Os dados da pesquisa são constituídos por seis entrevistas entre os assentados de um projeto de assentamento da Reforma Agrária do interior do Rio Grande do Sul, sendo utilizada a técnica de análise de conteúdo. Considerando que os entrevistados narram suas experiências individuais e coletivas, as autoras concluem que "o trabalho" foi fundamental na organização das famílias até o campo, e que "o trabalho" no lote do assentamento constitui um princípio educativo para essas famílias, sobretudo a partir das escolhas que fazem no processo produtivo.

$\mathrm{Na}$ sequência, apresentamos o trabalho intitulado "Los directores(as) de las escuelas primarias rurales como los principales maestros de sus subordinados", de Aguilera, da Universidad de Artemisa, Cuba. Nesse artigo, a autora traz um pouco de suas reflexões como formadora pedagógica na universidade. Assim, o objetivo do trabalho é propor um sistema de ações de formação para aprimorar as habilidades dos diretores de escolas primárias rurais cubanas como principais professores de seus subordinados. Aguilera afirma que o uso de diferentes métodos, como pesquisa, entrevista, observação participante e análise documental, permitiu caracterizar o estado inicial, fundamentando a proposta formativa e avaliando os resultados de sua aplicação, além de permitir que os diretores assumam o papel de professor de seus colegas de trabalho.

Já no artigo "Escola em tempo integral no campo: conflitos de ideias", de Silva e Sales, da Universidade Estadual de Mato Grosso do Sul - UEMS, os autores apresentam uma análise a respeito de discursos e conceitos referentes à Educação de Tempo Integral, apontando algumas ideias da população camponesa de um município do interior de Mato Grosso do Sul. A metodologia utilizada envolve entrevistas semiestruturadas e conversas informais com os pais de alunos de uma escola rural. A pesquisa revelou que grande parte da comunidade do campo é desfavorável a esta política e que, apesar das boas intenções, a 
implantação da escola de tempo integral evidencia a manutenção de certo descaso, por parte do Estado, para com a população do campo.

O último artigo, "Movimentos sociais e conquista do ensino superior: a formação de Pedagogos para a Educação do Campo", de autoria de Menezes, Faustino e Chaves, vinculadas à Universidade Estadual de Maringá - UEM, apresenta reflexões acerca de uma experiência de formação de pedagogos para escolas do Campo realizada pela UEM em parceria com o Movimento dos Trabalhadores Rurais Sem Terra (MST). Trata-se de uma pesquisa bibliográfica, associada a observações, registros das experiências desenvolvidas em diferentes espaços e momentos do curso, aulas, visitas às escolas do campo e, sobretudo, estudos, orientações e intervenções pedagógicas em um programa de iniciação à docência. As autoras afirmam que os Centros de Formação são espaços que exercem papel fundamental na gestão democrática dos processos formativos demandados pelos movimentos sociais. A atuação do movimento social, em parceria com universidades, demonstrou ser possível outra formação, que humanize a todos e desenvolva a consciência de luta por direitos e igualdade social.

"O conceito de natureza na Educação do Campo", de Miranda e Robaina, ambos da Universidade Federal do Rio Grande do Sul - UFRGS, abre os ensaios publicados nesta edição da RBEC. De abordagem teórica e perspectiva histórica, o manuscrito analisa o conceito de natureza em consonância com a Educação do Campo. Nessa perspectiva, os autores afirmam que o conceito de natureza está implicado nessa modalidade de educação, pois, segundo eles, a Educação do Campo possibilita construir um sentimento de pertencimento nos sujeitos nela envolvidos no processo educativo.

O próximo ensaio se refere ao trabalho: "A construção da categoria analítica "Campo" no Brasil - Possibilidades à Educação do Campo", de Claro e Pereira, vinculados à Universidade Federal do Rio Grande - FURG. Os autores ressaltam a categoria "campo" na pesquisa educacional brasileira. Segundo esses pesquisadores, há muitas relações entre a agricultura e sua constituição, contudo, essas relações não deixam claro outras atividades que não estejam vinculadas diretamente à categoria "trabalho" presente no meio rural.

Por fim, a resenha publicada na RBEC intitulada "A atualidade de "Os Condenados da Terra" de Frantz Fanon, da obra "Fanon, F. (1968). Os Condenados da Terra. Rio de Janeiro, RJ: Editora Civilização Brasileira", de autoria de Oliveira Filho, da Universidade do Estado do Rio de Janeiro - UERJ fecha este número da revista. O autor destaca que a obra do intelectual francês Frantz Fanon, publicada originalmente em 1961, diz respeito à colonização e seus principais efeitos causados às pessoas da época, especificamente das nações do sul. $\mathrm{O}$ autor destaca que essa obra foi fundamental para esboçar o cenário político, histórico, cultural e psíquico da colonização na Argélia e na África.

É importante ressaltar que ao enfatizar a figura do eterno intelectual brasileiro Paulo Freire, que completaria 106 anos neste ano, na capa deste número da RBEC, produzida a partir de uma obra de artes visuais confeccionada com diferentes sementes, por estudantes da Licenciatura em Educação do Campo da Universidade Federal do Tocantins, campus de Tocantinópolis, é uma forma de homenagear Freire pela sua relevante e presente contribuição à educação brasileira e internacional.

A Revista Brasileira de Educação do Campo agradece aos autores(as) pela submissão de trabalhos ao periódico e aos avaliadores(as) que contribuíram nas emissões de pareceres e revisões dos manuscritos apresentados neste número e também ao longo de 2017. Gostaríamos de destacar que, a partir do ano de 2018, a revista adotará a periodicidade quadrimestral, o que possibilitará uma ampliação do número de artigos publicados no periódico, contribuindo, portanto, para a produção e disseminação de conhecimento para a Educação do Campo e educação em geral. 
Desejamos a todos e a todas boas leituras e um feliz 2018!

\section{Como citar este editorial / How to cite this editorial}

APA:

Araújo, G. C., \& Silva, C. (2017). A Educação do Campo na pesquisa educacional brasileira. Rev. Bras. Educ. Camp., 2(2), 442-446.

ABNT:

ARAÚJO, G. C.; SILVA, C. A Educação do Campo na pesquisa educacional brasileira. Rev. Bras. Educ. Camp., Tocantinópolis, v. 2, n. 2, p. 442-446, 2017.

\section{ORCID}

Gustavo Cunha de Araújo

(iD) $\underline{\text { https://orcid.org/0000-0002-1996-5959 }}$

Cícero da Silva

(iD) https://orcid.org/0000-0001-6071-6711 